\section{Quantitative analysis of the surgical exposure and surgical freedom between transcranial and transorbital endoscopic anterior petrosectomies to the posterior fossa}

TO THE READERSHIP: Not long ago, we were notified of an inadvertent error in the legend to Fig. 3 in our recent article (Noiphithak R, Yanez-Siller JC, Revuelta Barbero JM, et al: Quantitative analysis of the surgical exposure and surgical freedom between transcranial and transorbital endoscopic anterior petrosectomies to the posterior fossa. J Neurosurg [epub ahead of print August 3, 2018. DOI: 10.3171/2018.2.JNS172334]).

We had mistakenly neglected to acknowledge that the upper panel of Fig. 3 contains a screenshot of copyrighted material from the AppSurgeOn - 3D Skull Atlas, which is produced by UpSurgeOn S.r.l. We issued a formal letter to Dr. Federico Nicolosi, CEO and founder of UpSurgeOn, to express our sincere apologies for the misunderstanding. To our fortune, he has granted us permission to use the copyrighted material as a basis for our artwork.

We apologize for the oversight, and we appreciate being able to correct the legend to Fig. 3, as shown on the following page. The article has been corrected online as of November 16, 2018.

Daniel M. Prevedello, MD The Ohio State University, Columbus, $\mathrm{OH}$

CORRESPONDING ARTICLE See pp 569-577. INCLUDE WHEN CITING

Published online November 16, 2018; DOI: 10.3171/2018.10.JNS172334a.

CAANS 2019, except where prohibited by US copyright law 


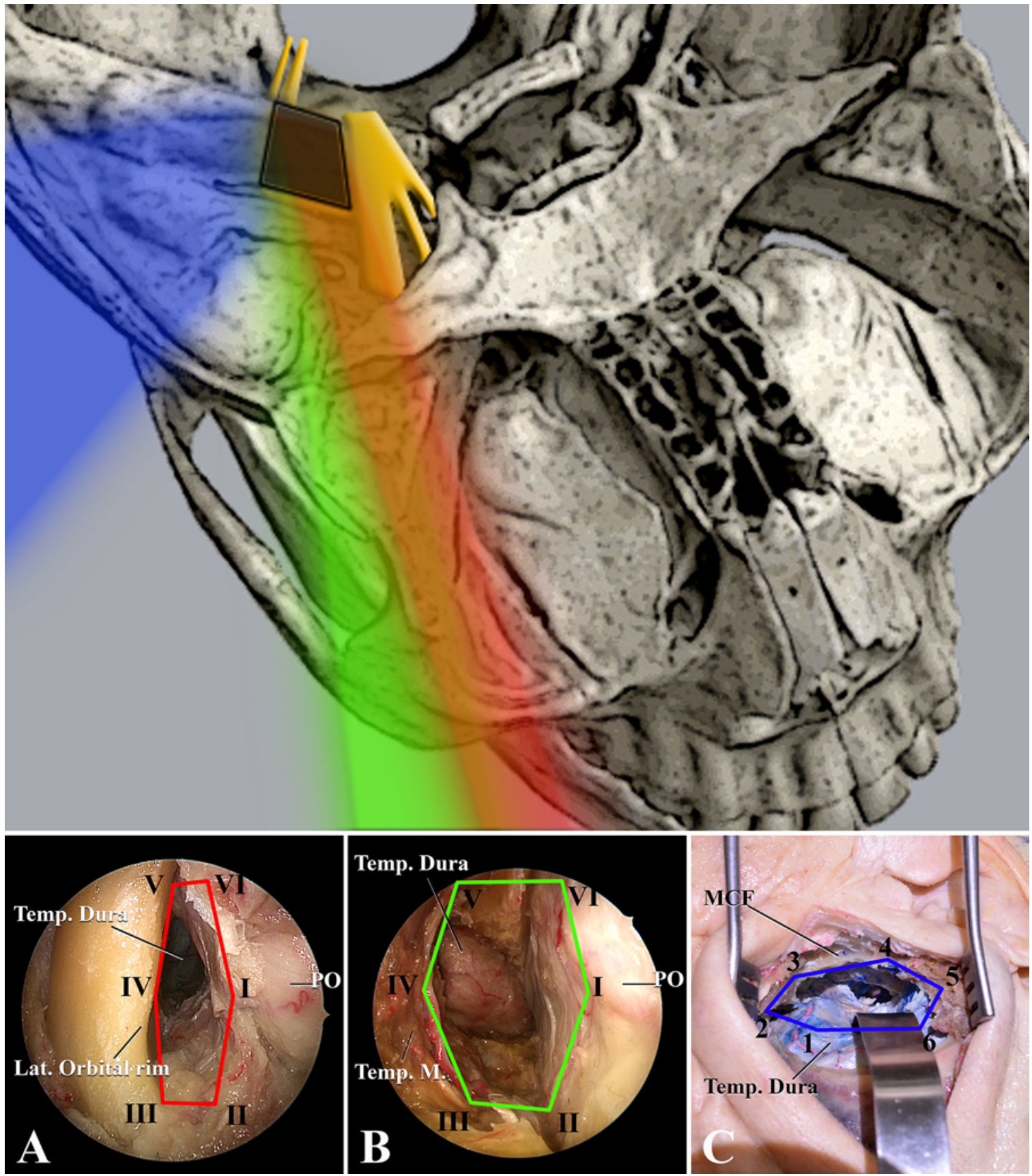

FIG. 3. Illustration of the trajectory of the LTOA (red area), LOWA (green area), and ATPA (blue area) and demonstration of the method used to collect the measurements of surgical freedom for LTOA (A), LOWA (B), and ATPA (C). Details are described in the Methods section. (C) The Ohio State University; used with permission. Base art in upper panel: @ UpSurgeOn S.r.l.; modified and used with permission. Figure is available in color online only. 